\title{
Learning Styles and Preferred Learning Modalities in the New Normal
}

\author{
Reynaldo Abrea Cabual \\ Nueva Ecija University of Science and Technology, Cabanatuan, Philippines \\ Email: racabual50@gmail.com
}

How to cite this paper: Cabual, R.A. (2021) Learning Styles and Preferred Learning Modalities in the New Normal. Open Access Library Journal, 8: e7305.

https://doi.org/10.4236/oalib.1107305

Received: March 11, 2021

Accepted: April 5, 2021

Published: April 8, 2021

Copyright (C) 2021 by author(s) and Open Access Library Inc.

This work is licensed under the Creative Commons Attribution International License (CC BY 4.0).

http://creativecommons.org/licenses/by/4.0/

\begin{abstract}
Learning is a never-ending process, and a process is an event that leads to a specific outcome. Understanding will not be accomplished if challenges will cause the learning process to be delayed or stopped. A successful learning plan will resolve these challenges, resulting in learning that is personalized to the learner's needs. The mismatch will grow as a result of the ineffective use of approaches, techniques, and tactics with the learners. Successful teaching and student learning can be achieved by recognizing the learner's style and preferred learning modalities. Each student has his or her own learning style and preferences. Some people discover their dominant learning style, while others use various learning styles in different circumstances. It contradicts Kolb's learning style theory which claims that people are born with a preference for a particular learning style. The study relied on Neil Fleming's VARK model of learning. This model emphasizes that students have different "preferred learning modes," or ways of processing information. The acronym VARK stands for Visual, Auditory, Reading/Writing Choice, and Kinesthetic learning styles. During the first semester of the Academic Year 2020-2021, this study sought to ascertain the various learning styles (visual, auditory, $\mathrm{read} /$ write, and kinesthetic) and preferred learning modalities of second-year college students. Via the use of "Google Forms," the students completed a personalized questionnaire focused on Fleming's VARK Learning Styles and preferred learning modalities. The results of the responses were downloaded in spreadsheet format from Google Forms. A total of 199 students served as respondents to the survey. The vast majority are "visual and read/write." The self-learning package (hardcopy of modules) and the teachers' PowerPoint presentations are the chosen learning modalities. Students' learning styles and preferred learning modalities are closely linked, but there are no substantial differences when classified by sex and area or major of specialization. It is recommended that teachers use the Fleming learning styles instrument at the beginning of the class to gain a solid understanding of what to teach and how
\end{abstract}


to treat their students in terms of pedagogies in order to keep students involved in the teaching and learning activities. Furthermore, since the pandemic is still widespread across the world, face-to-face communication is forbidden. Teachers and students must adapt to the New Normal's demands, despite the fact that it comes with financial constraints. School administrators must provide the necessary equipment so that teachers can deliver quality instruction in an effective and efficient manner.

\section{Subject Areas}

Psychology, Sociology

\section{Keywords}

Learning Styles, Visual, Auditory, Read/Write, Kinesthetic, Learning Modalities

\section{Introduction}

Teachers and students alike have been shocked by the potential impact on teaching and learning only a few months after the pandemic was announced. Digital and online delivery modes, mixed or versatile delivery modes, synchronous or asynchronous delivery modes, or a mixture of all these alternative delivery modes of teaching have largely replaced conventional face-to-face training. As a result of the college's survey, the online interactive method of teaching and learning has been used from the start. The issues surfaced about a month after it was introduced. The students became aware of the financial costs associated with the holding of online or virtual classes, such as the need to purchase a laptop/desktop, or an Android phone that is WIFI compatible, as well as a good internet connection, in order to fulfill the requirements for virtual or online classes. Teachers are affected by the difficulties that students face. It's also evident that the pandemic had an effect on teachers' and students' teaching and learning practices.

This research was carried out in the hopes of making an impact. It concentrated on identifying the Learning Styles and Preferred Learning Modalities of students in the New Normal. This was believed to respond to the students' difficulties during the pandemic. Similarly, after the learning patterns have been established, teachers will have baseline data to use in planning the subjects that will be taught to them. Even if a pandemic occurs, the known subjects are the most important for students to understand. The teachers' methods or techniques should also reflect the students' learning styles and preferred learning modalities.

Generally, this study aimed to determine the different learning styles (visual, auditory, read/write, \& kinesthetic) and second year college students' preferred learning modalities during the first semester of the Academic Year 2020-2021. 
Specifically, the following questions were answered:

1) How may the profile of the student-respondents be described in terms of:

a) Age:

b) Sex; and

c) field of specialization?

2) How may the learning styles of the students be described in terms of:

a) Visual;

b) Auditory;

c) Reading/Writing; and

d) Kinesthetic?

3) How may the preferred modalities of the students be described in terms of:

a) Self-learning kit (hardcopy of the modules);

b) Online (virtual classes:

c) PowerPoint on the topics;

d) Self-learning kit (soft copy of the modules); and

e) video recordings on the topics?

4) Is there a significant difference in the learning styles of the student-respondents when grouped based on sex and field of specialization?

\section{Literature and Methods}

Learning is a continuous process, and a process is actions that lead to a result. In this situation, learning barriers can result in delay or stop the learning process. However, an effective learning strategy can overcome those barriers to create learning that suits the learner. One of those barriers is the mismatch in the teaching-learning approach. An inappropriate way of using methods, techniques, and strategies to the learners may lead to this barrier. Recognizing the learner's style of learning can be lead to effective learning.

Every student has a learning style and learning preferences that are useful and helpful to them. Some find their dominant learning style, but others use different learning styles in other situations. In contrast to Kolb's learning style theory, different people naturally prefer a specific single different learning style, meaning to say everyone has a unique learning style.

The teachers need to understand how their students learn, but they must understand their learning style. Teachers for many years found out that students are unique individuals; they have their preferred learning style that suits them in understanding the lesson better. Faculty should think that knowing the students learning style is the key to unlock the classroom with a teacher knowledgeable in making the class prepared and can match the student's preferences with appropriate method and technique.

One of the things that educators should know in the learning process is to be aware that they are diverse individuals, especially in their learning styles. Almost all educators know that different learning styles exist; integrating this into a classroom has not been significant. Understanding these learning styles is one 
way of creating a classroom with the higher success of past students. Then faculty should understand these styles to create more appropriate instruction for the students. Student's performance may relate to their learning preferences. The student's success is partly dependent on the teacher's understanding of their learning styles.

Student-centered is one of the approaches that create more stability between the teacher and student, each playing a role in the learning process. While the teachers still hold authority, they act more as facilitators, coach students, and assist them in their learning (Lathan, 2021) [1]. For this approach to become effective, the teachers should consider the students preferred learning styles. If students are aware of their learning styles, they will be able to cope with this approach with ease.

Both teaching and learning styles play an essential role in learning development and achievement. Thus, researchers have paid great attention to discovering the students' learning styles, particularly under the New Normal.

The VARK model of students' learning styles, developed by Neil Fleming, is commonly used by most researchers. VARK stands for Visual, Auditory, Reading/Writing Preference, and Kinesthetic. Students have different approaches to how they interpret information, which is referred to as "preferred learning modes" in the model.

Visual learning style prefers images, maps, and graphic organizers to access and understand new information.

Listening and speaking in seminars and group discussions help auditory learners understand new material. Students benefit from the use of mnemonic devices and use repetition as a study strategy.

Read and Write learning style learns best through words. These students may present themselves as copious note-takers or avid readers and translate abstract concepts into words and essays. The kinesthetic learners best understand information through a tactile representation of data. Cherry (2019) [2] mentioned that these students are hands-on learners and learn best by figuring things out by hand. This model identifies students learning styles, and allowing students to access the information they are comfortable with, will increase their academic confidence. The teacher gains a better perspective on implementing these learning styles into lesson plans and study techniques.

The main ideas of VARK are outlined in the book Learning Styles Again: VARKing up the right tree (Fleming and Baume, 2006) [3]; behavior and learning have a significant influence on the students preferred learning styles, and the preferred learning modalities should be associated with appropriate learning strategies, and the information accessed through students' use of their modality preferences shows an increase in their levels of comprehension, motivation, and metacognition.

Learning styles make an essential component of how the teacher will demonstrate the students' knowledge to understand what is being taught easily (Busi- 
laoco et al., 2014) [4]. In a study conducted by Rezaeinejad (2015) [5] on the Learning Styles and Its Relationship with Educational Achievement among Iranian High School Students, he found out that knowing the students' learning style will help the teacher deliver the lesson that students can cope easily, make diverse teaching strategies, and lead to their educational achievement.

These studies are supported by the first distinctive feature and guiding principle of the Philippines' DepEd K to 12 Basic Education Program (2012) [6]. The learner is the very reason for the entire curriculum system. Its primary emphasis is on the learner's holistic learning and growth. An instructor provides an environment in which the learner enjoys learning, participates in meaningful learning activities, and achieves success because he or she is valued, embraced, and feels secure, even if he or she makes mistakes during his or her learning exploration. He/she is empowered to make choices to become responsible for his/her learning in the classroom and for a lifetime.

A group of psychologists stated that there is no adequate evidence-based to justify incorporating learning style assessments into general educational practice. Thus, limited education resources would be devoted to adopting other educational practices with a robust evidence-based increase in numbers. According to Rohrer and Pashler (2012) [7], given the scarcity of methodologically sound studies of learning styles, assuming that all potential learning styles have been studied may be a mistake. More research into the use of learning style tests in teaching may be necessary in some situations, but it must be done properly.

Jun Sun (2009) [8] stated in an article Learning and Individual Differences, attitude formation in human learning affected individual learners' experiences with various learning objects in particular learning contexts. It hypothesizes that the learner's object-related perceptions, personality traits, and situational perceptions may have different relationships with the general attitudes towards the learning objects and the specific attitude. Further, Hatami (2012) [9] described learning style as not in itself ability but rather a preferred way of using one's abilities. According to Sternberg and Grigorenko [10], there are three main motivations or interests in studying styles; understanding, anticipating, and enhancing educational achievement; and improving vocational selection, instruction, and potential placement. Individuals have different learning styles. That is, they differ in their "natural, habitual, and preferred way of absorbing, processing, and retaining new information and skills" (Reid, 1995) [11]. Besides, the study results suggested that there are substantial differences in learning between Australia and China. As a result, when structuring course offerings for students in China, program managers must consider these disparities (Heffernan, et al. 2010) [12].

\section{Methodology}

The quantitative and qualitative methods to solicit the responses of the respondents were used. 
Fellows and Liu (2008) [13] said that quantitative research methods are usually adopted because they are scientific methods and provide immediate results. Another reason behind selecting this approach is that it is more efficient, can test hypotheses, and always targets clarifying features, matter them, and build statistical models to describe what is discovered during research. According to Matthews \& Ross (2010) [14], quantitative research methods are fundamentally put on collecting data set up, and that could be displayed numerically. Generally, quantitative data is accumulated when a researcher has followed the positivist epistemological way and data are collected that may be scientifically analyzed.

In this study, the learning styles and the preferred learning modalities were treated quantitatively. The students were asked to accomplish the 16 sets of questions for their learning styles using Flemings VARK, which was customized and subjected to validation. There were four questions for each of the four types of learning styles, which are numbered from one to 16 . The questions were ramdomly positioned. For each question, the four learning types were represented. It was tallied using frequency counts, tabulated, interpreted and analyzed. The data on the learning styles and preferred learning modalities were collected through Google Forms.

Since the pandemic is ongoing, purposive sampling was used. There were seven sections of the second year college students, which totaled 199. According to Lee (2011) [15], purposive sampling is an acceptable kind of sampling for special situations. It uses the judgment of an expert in selecting cases or it selects cases with a specific purpose in mind. Purposive sampling is used most often when a difficult-to-reach population needs to be measured.

The link was provided to all identified second year students during the first semester of the Academic Year 2020-2021. Thirty days (November 16 to December 15) were given to them to submit their responses. The 199 chosen students accomplished and submitted their responses via Google Forms. They are those with strong internet connectivity, have gadgets or android phones, which are WiFi ready, and financially capable.

A test of difference using Chi-square was used to determine if there is significant difference between the learning styles when grouped based on sex and their preferred learning modalities.

The qualitative analysis, a non-numerical data collection approach focused on empirical observation was also used to analyze the relationship of the learning styles and the preferred learning modalities, particularly on the profile variables on sex, and field/major of specialization.

Qualitative research is mainly found in disciplines where the target is on reason and information such as sociology, interpersonal anthropology, and psychology rather than on predictions (Hakim 2000) [16]. This is appropriately applicable because it is pandemic time. Bryman and Bell (2007) [17] explained that qualitative research is a study strategy that implies the relationship between theory and research and usually emphasizes how theories were made. Qualitative 
research is inductivist, constructionist, and interpretivist, but qualitative researchers always don't subscribe to all three of these methods.

\section{Results and Discussions}

The following tables show the survey results regarding the learning styles and the College of Education's second-year students' preferred learning modalities at the Nueva Ecija University of Science and Technology. This part includes the profile of the students, the learning styles, and the preferred learning modalities.

\subsection{Profile of the Students}

This portion includes the age, sex, and field of specialization of the students presented in Table 1 and Table 2.

The students' AGE and SEX profiles are shown in Table 1. It is shown from the Table that the age distribution of students varies. The majority of students are females with 175 (87.44\%), 19 years old, comprising $50.75 \%$ of the total respondents. It is followed by $69(34.67 \%)$ students whose age is 20 ; 18 (9.05) of them are 21 years old; four (2.01\%) of the students are 18 years old, and there is one $(0.50 \%)$ who is 35 . There are $24(12.56 \%)$ male respondents.

The majority of the respondents are females between the ages of 19 and 20 . According to the results, the age distribution of the students differs. In terms of learning, age is not a factor. It is often proposed that a person's career may be pursued regardless of his or her age as in the case of the 35-year-old who keeps going to school.

Table 1. Age and sex of the students.

\begin{tabular}{cccccc}
\hline Age & f & Percentage & Sex & f & Percentage \\
\hline 18 & 4 & $2.01 \%$ & Male & 24 & $12.56 \%$ \\
19 & 101 & $50.75 \%$ & Female & 175 & $87.44 \%$ \\
20 & 69 & $34.67 \%$ & Total & 199 & $100.00 \%$ \\
21 & 18 & $9.05 \%$ & & & \\
22 & 6 & $3.02 \%$ & & & \\
35 & 1 & $0.50 \%$ & & & \\
Total & 199 & $100.00 \%$ & & &
\end{tabular}

Table 2. Field of specialization of the students.

\begin{tabular}{ccc}
\hline Field of Specialization & f & Rate \\
\hline General Science & 27 & $13.57 \%$ \\
English & 31 & $15.58 \%$ \\
Industrial Education & 62 & $31.16 \%$ \\
Technology and Livelihood Education & 79 & $39.70 \%$ \\
Total & 199 & $\mathbf{1 0 0 . 0 0 \%}$ \\
\hline
\end{tabular}


Table 2 presents the field of specialization of the students. It is reflected on the Table, the Technology and Livelihood Education program/major dominates the group of respondents with 79 (39.70\%), closely followed by Industrial Education program/major with $62(31.16 \%)$, the English major with 31 (15.58\%), and the General Science major with 27 (13.57\%).

According to the findings, the Bachelor of Technology and Livelihood Education and the Bachelor of Industrial Education are the most common program/major choices among second-year students. This is supported by the college's Guidance and Testing office, which reclassified the students based on their preferences or inclinations in the particular program. Furthermore, the Commission on Higher Education (CHED) sets a cap on the number of non-priority courses or programs offered in an educational institution. The university instructed the college to reduce the number of blocks or parts to comply with specific mandates. As a result, only two blocks have been created for Industrial and Technology Education.

This result also suggests that, even though the curriculum seemed to be geared toward male students, female students dominate industrial, technology, livelihood education, and secondary education. Furthermore, when choosing a course or class, students choose the program or course they believe will lead to a potential job.

\subsection{The Learning Styles of the Students}

The Learning Styles of the students are reflected in Table 3. It is shown in the Table that the majority of the students are "visual" with 105 (52.76\%); the auditory students are $36(18.09 \%) ; 35$ (17.59\%) are kinesthetic, and there are 23 (11.56\%) who are read/write.

The study's findings revealed that the students' group is "visual", and the rest are distributed to the other three learning styles. Felder \& Solomon (2007) [18] explained that visual learners remember best what they see pictures, diagrams, flow charts, timelines, films, and demonstrations. They tend to find diagrams, sketches, schematics, photographs, flow charts, or any other visual representation of course material that is primarily verbal very useful to learn. They use concept maps listing key points, enclosing them in boxes or circles, drawing lines between concepts to show connections. The color code notes with a highlighter so that everything relating to one topic is the same color.

Table 3. Learning styles of the students.

\begin{tabular}{ccc}
\hline Learning Styles & f & Percentage \\
\hline Visual & 105 & $52.76 \%$ \\
Auditory & 36 & $18.09 \%$ \\
Read/Write & 23 & $11.56 \%$ \\
Kinesthetic & 35 & $17.59 \%$ \\
Total & 199 & $100.00 \%$ \\
\hline
\end{tabular}


"Each child possessed unique talents and skills," Aristotle said, noting that young children differed from one another. Carl Jung, an observational psychologist, developed a psychological type theory, which is one of the first learning style theories (Cherry, 2019) [2]. Various learning styles were evaluated and identified by Jung. Reflective versus impulsive learning styles, for example, or random versus sequential learning styles, are bipolar individuals that embody two broad-spectrum extremes. On the other hand, a learner who falls on the spectrum is value-neutral since each height has advantages and disadvantages (Dörnyei, 2005) [19].

In a research titled Learning Styles and Students' Achievement in Science, what is being taught has less impact on learners' achievement than the way materials are presented. In other words, learning styles make an essential component of how the teacher will demonstrate the knowledge for the students to understand what is being taught easily. (Busilaoco et al., 2014) [4]. In another study, Rezaeinejad (2015) [5] evaluated the Learning Styles and Its Relationship with Educational Achievement among Iranian High School Students. He found out that knowing the students' learning style will help the teacher deliver the lesson that students can cope easily, make diverse teaching strategies, and lead to their educational achievement.

Teachers must cater to the needs of visual students by creating appropriate instructional materials, as they learn best when they can see what they are studying. The teacher's teaching strategies and approaches must be compatible with the learning styles of the students. At the beginning of each class, a learning style diagnosis must be given. Since the pandemic is still ongoing, changes to the syllabus should focus only on the most critical learning competencies while maintaining the highest possible quality of content delivery.

\subsection{Preferred Learning Modalities of the Student-Respondents}

The students' preferred learning modalities are shown in Table 4. The self-learning kit (hardcopy of the modules) earned the highest percentage, 66.67 percent, and was ranked first. Video recordings on the topics come in second with 42.71 percent, followed by the self-learning kit (soft copy of the modules) in third place (35.18 percent), online (virtual classes) in fourth place (30.65 percent), and PowerPoint on the topics in fifth place (12.56 percent) among the students' preferred modalities.

Table 4. Preferred learning modalities of the student-respondents.

\begin{tabular}{ccc}
\hline Modalities & Percentage & Rank \\
\hline Self-learning kit (hardcopy of the modules) & $66.67 \%$ & $1^{\text {st }}$ \\
Online (virtual classes) & $30.65 \%$ & $4^{\text {th }}$ \\
PowerPoint on the topics & $12.56 \%$ & $5^{\text {th }}$ \\
Self-learning kit (soft copy of the modules); & $35.18 \%$ & $3^{\text {rd }}$ \\
Video recordings on the topics & $42.71 \%$ & $2^{\text {nd }}$ \\
\hline
\end{tabular}


The results are intriguing because most students chose the hardcopy of the modules amid the pandemic. It is suggested that they will be able to learn at their speed and in their own time with the modules provided by their respective teachers. Some of them are auditory. They are more likely to avoid participating in virtual/online classes due to their lack of access to the requisite technology, such as a laptop/desktop, smartphone, or Android phone.

The students' preferred learning modalities and their learning styles have been discovered to have a close connection. Since most students have reported multiple responses in their preferred learning modalities, the association between learning styles and preferred learning modalities was not statistically evaluated.

The Department of Education Secretary, Leonor Briones said that 8.8 million parents preferred printed modules, followed by blended learning, which is a combination of learning by modules, online classes, television, and radio (3.9 million parents), online learning (3.8 million), and educational television (1.4 million parents) (500,000 parents) in a report as cited by Bonz Magsambol dated July 30, 2020 [20].

\subsection{Significant Difference in the Student Respondents Learning Styles when Grouped Based on Sex and Field of Specialization}

Table 5 presents the difference between the students' learning styles when grouped based on sex.

The chi-square was used to test the difference between the students' learning styles when grouped based on sex and field of specialization.

With the computed $p$-value $=0.06$, the students' learning styles when grouped based on sex have no significant difference. The students' sex profile does not have a substantial difference with their learning styles. Males and females alike, when their learning styles were determined, yield no significant difference. There are attribution factors or reasons why there is no significant difference between these variables: first, the pandemic situation where the students tend to group themselves according to their being adjacent. Second, the students' modular approach of learning led the way for such groupings; and lastly, learning styles that vary from student to student did not surface in the present study.

Table 5. Test of difference between the learning styles of the students, when grouped based on sex.

\begin{tabular}{cccc}
\hline Learning Styles & Male & Female & Total \\
\hline Visual & 15 & 90 & 105 \\
Auditory & 4 & 32 & 36 \\
Read & 3 & 20 & 23 \\
Kinesthetic & 1 & 33 & 35 \\
Total & 25 & 174 & \multicolumn{2}{c}{ Not Significant } \\
Chi-square & $p$-value $=0.06$ & \multicolumn{2}{c}{. }
\end{tabular}


Whereas, in the study of Dobson (2010) [21], comparison between learning style preferences and sex, status, and course performance, the students were asked to select the single sensory modality they felt they preferred to use when internalizing information in the course. According to the findings, sensory modality preferences were related to both sex and course scores significantly. Those who chose the $\mathrm{K}$ modality, for example, scored considerably lower than those who chose the other three.

Table 6 shows the differences in learning styles among students when they are grouped by field of specialization.

With 104 students, the Table shows that the students' learning styles fall into the "visual" group. Due to the pandemic, they preferred to be visual, majoring in Science, English, Industrial, or Livelihood Education. They are afraid of contracting COVID-19 through physical interaction with their teachers. Furthermore, most students' financial circumstances may explain why they choose the FREE self-learning kit (hardcopy of the modules) prepared by their teachers.

With the computed $p$-value $=0.464$, the students' learning styles, when grouped based on field of specialization, have no significant difference.

This result suggests that the students' learning styles are unaffected by their chosen field of study. Furthermore, the findings can be interpreted based on the different learning styles of the students. For example, English majors place a greater emphasis on "visual" than one would think. They should have been in the categories of "read/write" or "auditory." It also applies to other areas (General Science, Industrial Education, \& Technology Education). They revealed themselves to be "visual" students. As a result, with a calculated p-value of 0.464, the test of the disparity between the students' learning styles and their area of specialization is rejected.

\section{Conclusions and Recommendations}

\subsection{Conclusions}

Most of the respondents are females and are 19 years old. Their program/major preference is the Bachelor of Technology and Livelihood Education and the Bachelor of Industrial Education. Though the program seemed to be for male students, female students dominate industrial education, technology and livelihood education, and secondary education.

Table 6. Learning styles of the students when grouped based on field of specialization.

\begin{tabular}{cccccc}
\hline Learning Styles & Science & English & Industrial & Livelihood & Total \\
\hline Visual & 20 & 16 & 32 & 37 & 104 \\
Auditory & 4 & 3 & 12 & 17 & 36 \\
Read & 1 & 4 & 7 & 11 & 23 \\
Kinesthetic & 2 & 8 & 11 & 14 & 35 \\
Total & 27 & 31 & 62 & 79 & 199 \\
Chi-square & & p-value $=0.464$ & & Not Significant \\
\hline
\end{tabular}


The majority of the students are "visual," with remaining three learning styles distributed evenly. Amid the pandemic, the majority of students chose the hardcopy of the modules. Through their respective teachers' modules, they will learn at their speed and on their own time. They are also kinesthetic, auditory, and read/write.

The learning styles and the preferred learning modalities were not statistically tested. However, there is a strong relationship between the learning styles and the students' preferred learning modalities, as revealed in the results. Most students have indicated multiple responses in their preferred learning modalities. Hence, it is far beyond to compare the two variables.

The students' learning styles, when grouped based on sex, have no significant difference. The students' sex profile does not have a substantial difference with their learning styles. Males and females alike, when their learning styles were determined, yield no significant difference. Several reasons contributed to this; first, the pandemic situation where the students tend to group themselves according to their being adjacent. Second, the students' modular approach of learning led the way for such groupings; and lastly, learning styles that vary from student to student did not surface in the present study.

Further, the students' field of specialization or major has no significant difference with their learning styles. The results can also be interpreted based on the variations in the students' learning styles. The English majors are more on "visual" than expected. They should have been into the "read/write" or "auditory" categories. It is also true to other fields (General Science, Industrial Education, \& Technology Education). They came out to be "visual" students.

Although the students preferred one thing in common: the self-learning kit (hardcopy of the modules) prepared by their teachers which ranked first, the test of correlation was not established with their learning styles due to the students' multiple responses in identifying other preferred learning modalities. Such selection may also be due to the students' financial situation because some of their parents have lost their jobs during the pandemic. Emerging issues might surface when the situation restores to the normal condition, i.e. testing the correlation of the students' profiles with their learning styles and preferred learning modalities.

\subsection{Recommendations}

The administration of a diagnosis of the learning styles and preferred learning modalities should be done at each class's opening. In this case, the teachers are guided with the baseline information they have of their students.

Teachers must cater to visual students' needs by creating suitable instructional materials since learning is best attained when they see what they are studying.

Other learning styles must also be addressed. The auditory, read/write, and kinesthetic students must also be given due importance. The teachers also need to have a variety of activities to respond to their students' specific needs. There should be equity and equality in attending to the interests, conditions, and level 
of abilities, particularly in this time of the pandemic.

There must be an alignment of the teacher's teaching strategies/approaches with the students' learning styles and preferred learning modalities.

There must be adjustments in selecting the topics incorporated in the syllabus or the teachers' academic plans; approved by the academic heads. The contents or topics should cover the essential learning competencies without sacrificing the content's quality of instructional delivery.

Since the pandemic situation is not yet over, asynchronous and synchronous approaches can still be used. In online learning, asynchronous learning is a student-centered teaching approach that is widely used. Its basic principle is that learning should occur at various times and places for each learner, as opposed to synchronous learning, which takes place at the same time and place for groups of learners or one learner and their teacher. Instructors usually set up a learning roadmap for students to follow at their own pace in asynchronous learning. Some examples of this method are creating online content with pre-recorded videos, PowerPoint presentations, a quiz, or an examination via Google Forms. Synchronous learning is any form of learning in which the learner(s) and instructor(s) meet an agreed time and place to facilitate learning. This approach involves in-person classes as well as live online meetings with the entire class or smaller groups. Students usually go along the learning path together in synchronous learning, assisted by a teacher who can encourage students to perform assignments and activities. The majority of online learning occurs asynchronously, with synchronous learning occurring only when there is a real need for live discussion or interaction or a strategy to foster community among students.

\section{Conflicts of Interest}

The author declares no conflicts of interest regarding the publication of this paper.

\section{References}

[1] Lathan, J. (2021) Complete Guide to Teacher-Centered vs. Student-Centered. https://onlinedegrees.sandiego.edu/teacher-centered-vs-student-centered-learning

[2] Cherry, K. (2020) How Jung's Theory of Personality Can Explain How You Learn. https://www.verywellmind.com/jungs-theory-of-personality-learning-styles-279516 $\underline{0}$

[3] Fleming, N. and Baume, D. (2006) Learning Styles Again VARKing up the RIGHT Tree! Educational Developments, 7, 4-7. https://www.scirp.org/reference/ReferencesPapers.aspx?ReferenceID=1223937

[4] Busilaoco, F.C. and Lao, S.R. (2014) Learning Style and Students' Achievement in Science. IAMURE International Journal of Multidisciplinary Research, 7.

[5] Rezaeinejad, M., Azizifar, A. and Gowhary, H. (2015) The Study of Learning Styles and Its Relationship with Educational Achievement among Iranian High School Students. Procedia-Social and Behavioral Sciences, 199, 218-224. https://doi.org/10.1016/j.sbspro.2015.07.509

[6] Department of Education K to 12 Basic Education Program (2012). 
http://www.deped.gov.ph

[7] Pashler, H., McDaniel, M., Rohrer, D. and Bjork, R. (2008) Learning Styles. Psychological Science in the Public Interest, 9, 105-119.

https://doi.org/10.1111/j.1539-6053.2009.01038.x

[8] Sun, J. (2009) How Object, Situation and Personality Shape Human Attitude in Learning: An Activity Perspectives and a Multilevel Modeling Approach. Learning and Individual Differences, 19, 314-319. https://doi.org/10.1016/j.lindif.2009.02.002 http://www.researchgate.net/publication/238292151

[9] Hatami, S. (2012) Learning Styles. ELT Journal, 67, 488-490. https://doi.org/10.1093/elt/ccs083

[10] Sternberg, R.J., Jarvin, L. and Grigorenko, E.L. (2010) Learning Disabilities, Giftedness, and Gifted/LD. In: Explorations in Giftedness, Cambridge University Press, Cambridge, 168-176. https://doi.org/10.1017/CBO9780511778049.010

[11] Reid, J.M. (1995) Learning Styles in the ESL/EFL Classroom. Heinle \& Heinle Publishers, Florence.

https://www.scirp.org/(S(351jmbntvnsjt1aadkposzje))/reference/ReferencesPapers.a spx?ReferenceID $=954130$

[12] Hefferman, T., Morrison, M., Basu, P. and Sweeney, A. (n.d.) Cultural Differences, Learning Styles and Transnational Education.

https://scholar.google.com.ph/citations

[13] Fellows, R. and Liu, A. (2008) Research Methods for Construction. 3rd Edition, Blackwell Publishing Ltd., Hoboken.

https://www.scirp.org/reference/referencespapers.aspx?referenceid=2665024

[14] Matthews, B. and Ross, L. (2010) Research Methods. Pearson Longman, London. https://www.scirp.org/(S(351jmbntvnsitlaadkposzje))/reference/ReferencesPapers.a spx?ReferenceID $=1745585$

[15] Lee, S. (2011) Population Parameter in Encyclopedia of Survey Research Methods: Course Hero.

https://www.coursehero.com/file/83409475/Population-Parameters-Lavrakas-2011p df

[16] Hakim, C. (2000) Work-Lifestyle Choices in the 21st Century: Preference Theory. Oxford University Press, Oxford.

[17] Bell, E. and Bryman, A. (2007) The Ethics of Management Research: An Exploratory Content Analysis. British Journal of Management, 18, 63-77. https://doi.org/10.1111/j.1467-8551.2006.00487.x

[18] Felder, R. and Solomon, B. (2007) Learning Styles and Strategies. http://www.ncsu.edu/felder-public/ILSdir/styles.htm

[19] Wagner, E. (2007) Book Review: Zoltán Dörnyei, 2005: The Psychology of the Language Learner: Individual Differences in Second Language Acquisition. Mahwah, NJ: Lawrence Erlbaum. 270 pp. \$29.95 (PB) ISBN 0-8058-6018-5. Language Teaching Research, 11, 506-509. https://doi.org/10.1177/13621688070110040802

[20] Magsambol, B. (2020) 8.8 Million Parents Prefer Modular Learning for Students-DepEd [Web Log Post].

https://www.rappler.com/nation/deped-says-parents-prefer-modular-learning-stud ents

[21] Dobson, J.L. (2010) A Comparison between Learning Style Preferences and Sex, Status, and Course Performance. Advances in Physiology Education, 34, 197-204. https://doi.org/10.1152/advan.00078.2010 